\title{
Are You There?
}

\author{
Kate Sanford \\ Teachers College, Columbia University
}

With or without cameras on, my students always feel out of reach to me. There is a screen--and a few boroughs, in some cases even states or countries--between us. I can't tell how they're feeling; I can't watch their faces or their hands as they work on a piece for our writing class. The whole enterprise has started to feel epistolary. I am never sure if my recipient is going to respond, or if they've even received what I've sent them. I leave comments that may or may not be read. I send emails that sit in student inboxes, stacked between hundreds of others. In Zoom class, every question I ask feels like a million questions, and a gamble: Will you respond aloud, or will I see a response pop up in the chat? Do you need time to think? Is your internet slow? Are you there?

Everyone weighing in on the topic of remote learning suggests socioemotional check-ins with students. There are interactive slides, Do Nows, ice breakers. Everyone tells you that kids have a lot to deal with right now, that depression and anxiety are on the rise. I've tried the strategies, and all they do for me is confirm what everyone already knows. I spend a lot of time thinking about how to best teach students what I'm supposed to teach them and how to support them--and whether if, in this context, those two tasks are mutually exclusive.

As a break from the state test-oriented curriculum we're tethered to, the ELA (English Language Arts) teacher suggests a speech writing unit, and I'm immediately on board. The prompt for the students is to identify an issue in their community, argue for its urgency, and offer a solution or call to action. I'm hopeful that the students will find this intriguing, but it's hard to predict if, in this moment when they already feel overwhelmed, they will respond.

One student, K, has been in and out of classes. I can tell that she's bright, but she has been on the brink of failing for the entire school year. Even when she's there, she's only vaguely responsive. If I ask her how she is, she chats me back, fine. But one day, I receive a message on Google Classroom, and she's written to me: I drafted my speech if you have any free time to critique it let me know, $i$ want to know where i can improve, I'm not yet satisfied with it. :)

I open the document, and find that K's written a vehement prose poem. It's beautiful. I can hear her voice. I can feel what she's feeling: angry, frustrated, drowning. She indicts schools and teachers. She asks for understanding. Using data and her own personal experiences, she demands a radical restructuring of educational expectations. Her piece sophisticatedly met the demands of the academic assignment--and shared with me how she was and what she needed.

Eight months into the school year, I could finally hear her.

Kate Sanford is a high school writing and ENL teacher in New York City. Correspondence should be sent to E-mail: kms2305@tc.columbia.edu

(C) 2021 Sanford. This is an open access article distributed under the terms of the Creative Commons Attribution License, which permits the user to copy, distribute, and transmit the work provided that the original authors and source are credited. 